\title{
Análise morfométrica e de usos do solo da bacia hidrográfica do Arroio Can- diota, RS, Brasil
}

\author{
Roberto Nascimento de FARIAS ${ }^{1}$, Catarina da Silva PEDROZ0 ${ }^{1,2}$, Nelson Augusto Flores MACHA- \\ DO $^{2}$ \& Maria Teresa Raya RODRIGUEZ ${ }^{1}$
}

1 Programa de Pós-graduação em Ecologia, Instituto de Biociências, Universidade Federal do Rio Grande do Sul. Av. Bento Gonçalves, 9500, CEP 91.540-000, Porto Alegre, RS, Brasil. E-mail: betofarias.bio@gmail.com, catarina.pedrozo@ufrgs.br, raya. rodriguez@ufrgs.br.

2 Centro de Ecologia, Instituto de Biociências, Universidade Federal do Rio Grande do Sul. Av. Bento Gonçalves, 9500, CEP 91.540-000, Porto Alegre, RS, Brasil. E-mail: nelson.machado@ufrgs.br.

Recebido em 04/2014. Aceito para publicação em 06/2015.

Versão online publicada em 19/08/2015 (www.pesquisasemgeociencias.ufrgs.br)

\begin{abstract}
Resumo - 0 conhecimento dos fatores naturais e antrópicos que operam em escala de bacia hidrográfica é crucial para a gestão dos recursos hídricos, tendo em vista que os sistemas fluviais se organizam de forma hierárquica. Nesse sentido, este estudo tem por objetivo descrever as características morfométricas do relevo e da rede de drenagem, assim como, os usos do solo presentes na bacia hidrográfica do Arroio Candiota, RS, Brasil. Para isso, foram selecionadas 26 sub-bacias para análise de 15 variáveis morfométricas e oito classes de usos do solo. As sub-bacias em geral possuem riachos pouco sinuosos e baixa densidade de drenagem. Razão de circularidade, relação de relevo, declive e fator topográfico mostraram-se inversamente correlacionadas com a área das sub-bacias. Logo, as sub-bacias menores tendem a apresentar, no seu rio principal, um maior potencial de erosão e ser mais suscetíveis à inundação, pois é maior a probabilidade da sub-bacia inteira ser atingida simultaneamente pela chuva. A maior parte da bacia hidrográfica do Arroio Candiota $(59,31 \%)$, principalmente a sua metade leste, é ocupada por vegetação natural. As atividades de mineração e silvicultura estão mais associadas às regiões próximas às nascentes dos riachos enquanto agricultura e campo degradado se distribuem mais próximas ao curso principal do Arroio Candiota. Este estudo demonstra que as características morfométricas e os usos do solo variam espacialmente na bacia hidrográfica do Arroio Candiota e a distribuição de algumas atividades antrópicas está relacionada a características naturais, como relevo e disponibilidade hídrica. Palavras-chave: sistemas fluviais, gestão de recursos hídricos, influência antrópica.
\end{abstract}

Abstract - Morphometrical analysis and LAND uSE of the ARroio CANDiota WATERSHEd, RS, BRAZIL. The Knowledge of the natural and anthropogenic factors at watershed scale is crucial to management of water resources, considering that the river systems are organized hierarchically. In this sense, this study aims to describe the morphometric characteristics of relief and drainage network as well as land use in the Arroio Candiota watershed, RS, Brazil. For this, 26 catchments were selected to analyze 15 morphometric variables and eight land use classes. In general, the catchments showed low drainage density and streams with low sinuosity. Circularity ratio, relief ratio, slope and topographic factor were inversely correlated with the catchment area. Therefore, the smaller catchments tend to have greater potential for erosion in their main channel and increased susceptibility to flooding, because it is more likely the entire catchment be achieved simultaneously by rainfall. Most of the Arroio Candiota watershed (59.31\%), mainly its eastern portion, is occupied by natural vegetation. Mining and forestry are associated with the regions nearby of headwaters of streams while agriculture and degraded prairies are distributed closer to the main course of the Arroio Candiota. This study demonstrates that the morphometric characteristics and land use vary spatially in Arroio Candiota watershed and the distribution of some human activities is related to natural features such as relief and water availability.

Keywords: river systems, water resources management, anthropogenic influence. 


\section{Introdução}

Um sistema fluvial inclui toda a água superficial presente em uma bacia hidrográfica. De acordo com a classificação hierárquica de Frissel et al. (1986), ele é constituído por segmentos de riachos, que são porções da rede de drenagem delimitadas por duas confluências. Cada segmento, por sua vez, é composto por trechos de riacho (reachs), regiões muito homogêneas quanto ao declive, declividade do vale lateral e características da zona ripária. Em função da geomorfologia do leito e das características hidrológicas, um trecho de riacho pode ser dividido em poços e corredeiras que, por sua vez, podem ser subdivididos em microhábtitats, pelo tipo de substrato, profundidade e velocidade da água. Dessa forma, em função da organização hierárquica dos sistemas fluviais, os fatores naturais e antrópicos que ocorrem em escala de bacia hidrográfica influenciam fortemente as características locais (bióticas e abióticas) dos riachos.

Geologia, relevo e clima são os principais determinantes do funcionamento dos ecossistemas aquáticos lóticos em escala de bacia hidrográfica (Mesa, 2006). 0 clima e a geologia determinam o relevo da bacia hidrográfica e a interação desses fatores, por sua vez, determina os padrões encontrados na rede de drenagem. Segundo Richards et al. (1996), em escala regional, o clima e a geomorfologia afetam a hidrologia, a sedimentação, a entrada de nutrientes e a morfologia do canal, e as diferenças climáticas e geológicas entre as bacias hidrográficas determinam as características físico-químicas dominantes nos riachos. A influência do clima sobre a rede de drenagem também pode ocorrer indiretamente pelo seu efeito sobre a intensidade do escoamento superficial e da erodibilidade da superfície, aumentando o número de canais formados com o aumento na precipitação pluviométrica. Sendo assim, a análise morfométrica do relevo e da rede de drenagem de uma bacia hidrográfica é também uma avaliação indireta de fatores climáticos e geológicos (Eccker, 1984; Gordon et al., 2004), pois a rede de drenagem expressa o clima, a geologia, o relevo e o contexto tectônico prevalentes na bacia hidrográfica (Thomas et al., 2012). Além disso, a análise morfométrica fornece uma descrição quantitativa da geometria da bacia hidrográfica para entender as desigualdades na dureza da rocha, os controles estruturais, diatrofismo recente e a história geológica e geomorfológica da bacia hidrográfica (Strahler, 1964).

As atividades antrópicas desenvolvidas na bacia hidrográfica têm efeitos diretos e indiretos sobre as características locais, bióticas e abióticas, dos ecossistemas fluviais. A área antropicamente modificada em uma bacia hidrográfica é uma medida direta dos impactos antrópicos e pode ser correlacionada com indicadores da condição biótica e abiótica dos riachos (Gergel et al., 2002). As mudanças no uso e na cobertura do solo podem impactar os ambientes aquáticos e alterar as taxas de escoamento superficial, de aporte de sedimento, troncos e galhos, assim como poluentes (Gordon et al., 2004). As atividades antrópicas que afetam o aporte de água e sedimento e/ou o formato do canal, podem levar a uma cadeia complexa de mudanças que, em última instância, se manifestam em alteração e, possivelmente, degradação de nos riachos (Allan, 2004).

Neste contexto, este trabalho tem por objetivo descrever as características morfométricas e o uso e a cobertura do solo da bacia hidrográfica do Arroio Candiota e como essas características variam entre as sub-bacias que a compõem. Nesta bacia hidrográfica, estão presentes diversas atividades antrópicas, dentre elas agricultura, pecuária, silvicultura, mineração de carvão, mineração de calcário e geração térmica de eletricidade. Sendo assim, pode ser entendida como um modelo de estudo para investigar a influência dos fatores regionais sobre características locais dos riachos. Os resultados aqui apresentados poderão subsidiar novos estudos que visem determinar a influência dos fatores regionais sobre as características locais dos riachos.

\section{2 Área, materiais e métodos}

\section{1 Área de estudo}

A bacia hidrográfica do Arroio Candiota localiza-se no sudoeste do Estado do Rio Grande do Sul, entre as coordenadas geográficas $31^{\circ} 19^{\prime} 1,19^{\prime \prime}$

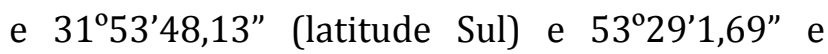
$53^{\circ} 54^{\prime} 54,00^{\prime \prime}$ (longitude Oeste) e abrange os municípios de Candiota, Pedras Altas e Pinheiro Machado (Fig. 1).

Segundo a classificação climática de Köppen, o clima da região é do tipo Cfa (subtropical com verões quentes e precipitação pluviométrica distribuída ao longo do ano). A letra " $\mathrm{C}$ " define climas mesotérmicos (temperatura média do mês mais frio inferior a $18^{\circ} \mathrm{C}$ e superior a $-3^{\circ} \mathrm{C}$, ao menos um mês com média igual ou superior a $10^{\circ} \mathrm{C}$ ). A letra "f" se refere ao clima ser sempre úmido (mês menos chuvoso com precipitação superior a $60 \mathrm{~mm}$ ). A letra "a" indica verões quentes (mês mais quente com média igual ou superior a $22^{\circ} \mathrm{C}$ ). 


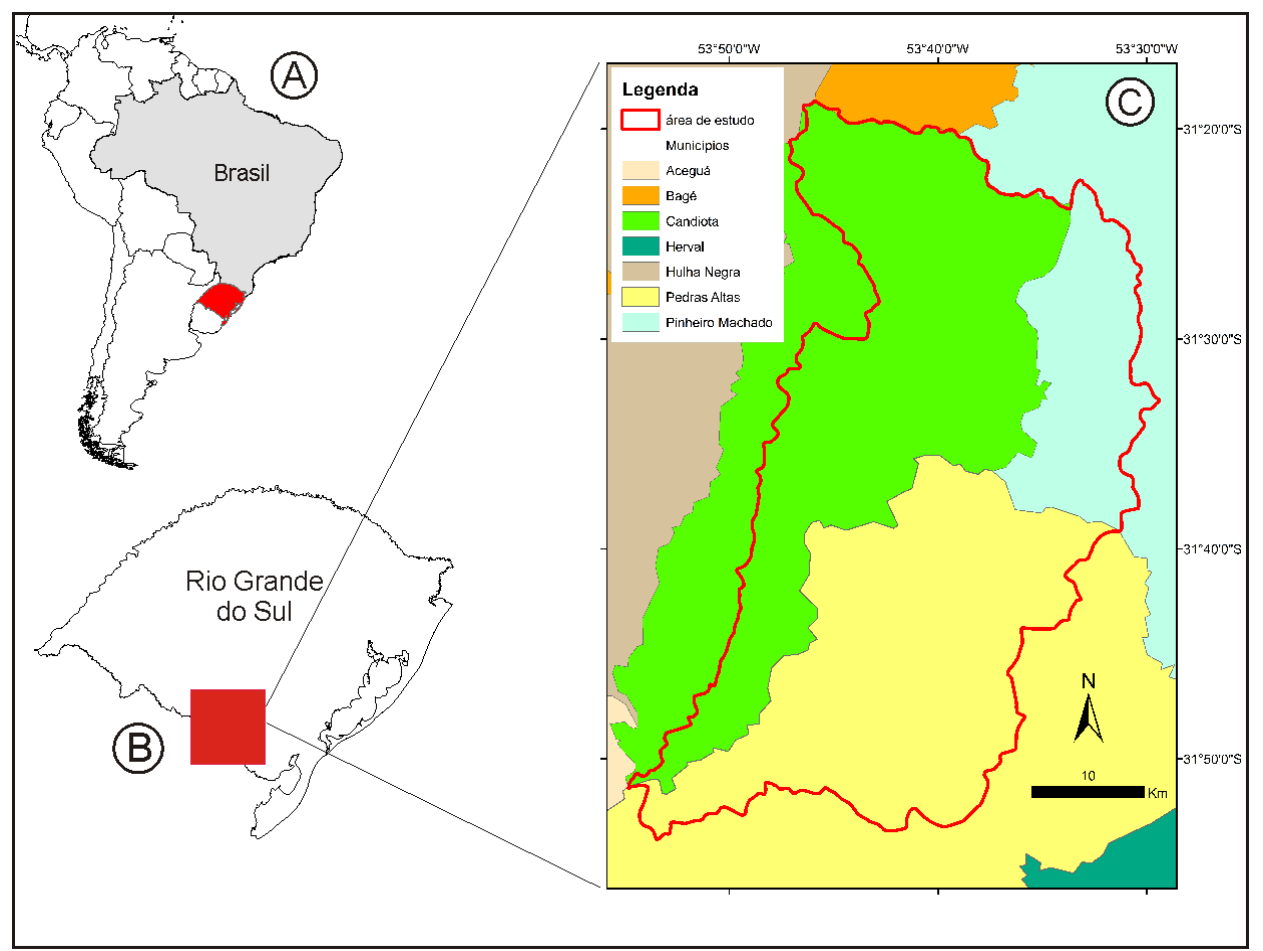

Figura 1. Localização da área de estudo em relação (A) à América do Sul, (B) ao Rio Grande do Sul e (C) aos municípios da região.

0 arcabouço geológico da bacia hidrográfica do Arroio Candiota é formado principalmente pelas rochas pertencentes a Bacia Sedimentar do Paraná, que se caracteriza regionalmente como uma extensa depressão deposicional situada na parte centro-leste do continente sul-americano. A litologia é constituída por arenitos finos, localizadamente grossos, cinza esbranquiçados intercalados com siltitos cinza-escuros, siltitos carbonosos e camadas de carvão (Strek et al., 2004). A região localiza-se no contato entre a Província Estrutural Mantiqueira e a Província Paraná. Na área de estudo, estão presentes os depósitos aluvionares atuais, os depósitos coluvionares, o Grupo Passa Dois (Formação Rio do Rastro, Formação Estrada Nova e Formação Irati), o Grupo Guatá (Formação Palermo e Formação Rio Bonito), o Grupo Itararé (Formação Rio do Sul), a Formação Guaritas, a Suíte Granítica Dom Feliciano Fácies sienogranito-stocks, o Granito Porfiróide Chácara São Jerônimo e o Complexo Metamórfico Porongos (CPRM, 2000).

Quanto aos tipos de solo, Cunha et al. (1998) dividem o município de Candiota em duas regiões distintas: norte-nordeste e sul-sudoeste. De acordo com esses autores, a região norte-nordeste contém solos antigos intensamente avermelhados, geralmente de média a baixa fertilidade, bem drenados e com alternâncias de textura, concentração de cascalhos, calhaus, pedregosidade e rochosidade. Por outro lado, na região sul-sudoeste, encontram-se solos que evoluíram no Quaternário, com a remoção progressiva das camadas sedimen- tares de nível superior, formando sempre solos parcialmente rasos. Ainda, segundo os autores, o município de Candiota contém, aproximadamente, $52 \%$ de terras que suportam uma agricultura intensiva contínua com cultivos anuais. Cultivos anuais intermitentes podem dispor de mais de 15 $\%$ da área. As áreas próprias para cultivos perenes ou pastagem cultivada totalizam $24 \%$; entretanto, se priorizados cultivos perenes, os solos bem drenados totalizam $43 \%$. Apenas $10 \%$ das terras íngremes ou rochosas não teriam uso recomendado para cultivo.

Na bacia hidrográfica do Arroio Candiota estão presentes diversas atividades antrópicas, tais como: mineração de carvão e de calcário, geração térmica de eletricidade, cimenteiras, agricultura, pecuária e silvicultura. A região possui a maior reserva carbonífera brasileira (cerca de $25000 \mathrm{~km}^{2}$ ) e é responsável por $38 \%$ das reservas de carvão brasileiro e $30 \%$ da mineração de céu aberto (Teixeira \& Pires, 2004). A silvicultura é uma das atividades que mais tem se expandido na bacia. Segundo Eger (2012), entre os anos de 2000 e 2009, a área de silvicultura mais que triplicou, ao mesmo tempo em que foi reduzida a área ocupada por mata nativa.

A bacia hidrográfica do Arroio Candiota integra a bacia hidrográfica do curso superior do rio Jaguarão e pertence à região hidrográfica do Litoral Sul, sendo os arroios Poacá e Candiotinha os principais afluentes do Arroio Candiota, em termos de cargas antrópicas (Guerra \& Ferraro, 2004). 
2.2 Divisão da bacia hidrográfica do Arroio Candiota em sub-bacias

0 presente estudo avaliou as características morfométricas e os usos do solo presentes na bacia hidrográfica do Arroio Candiota como um todo e em 26 sub-bacias contribuintes (Fig. 2). A bacia hidrográfica foi delimitada a partir da sua desembocadura no rio Jaguarão e as sub-bacias selecionadas com base em análise preliminar da rede de drenagem e do uso e da cobertura do solo. Para isso, foi utilizado o mapa de cobertura vegetal do
Bioma Pampa (Hasenack \& Cordeiro, 2006) e a Base Vetorial Contínua do Rio Grande do Sul (Hasenack \& Weber, 2010).

As sub-bacias foram selecionadas de forma a representarem juntas um gradiente de características morfométricas (do relevo e da rede de drenagem) e de intervenção antrópica (percentual da sub-bacia ocupada por atividades antrópicas). A seleção das sub-bacias considerou também a acessibilidade, isto é, a presença de estradas próximo à sua desembocadura. Dessa forma, os trechos de riacho nas desembocaduras das sub-bacias podem

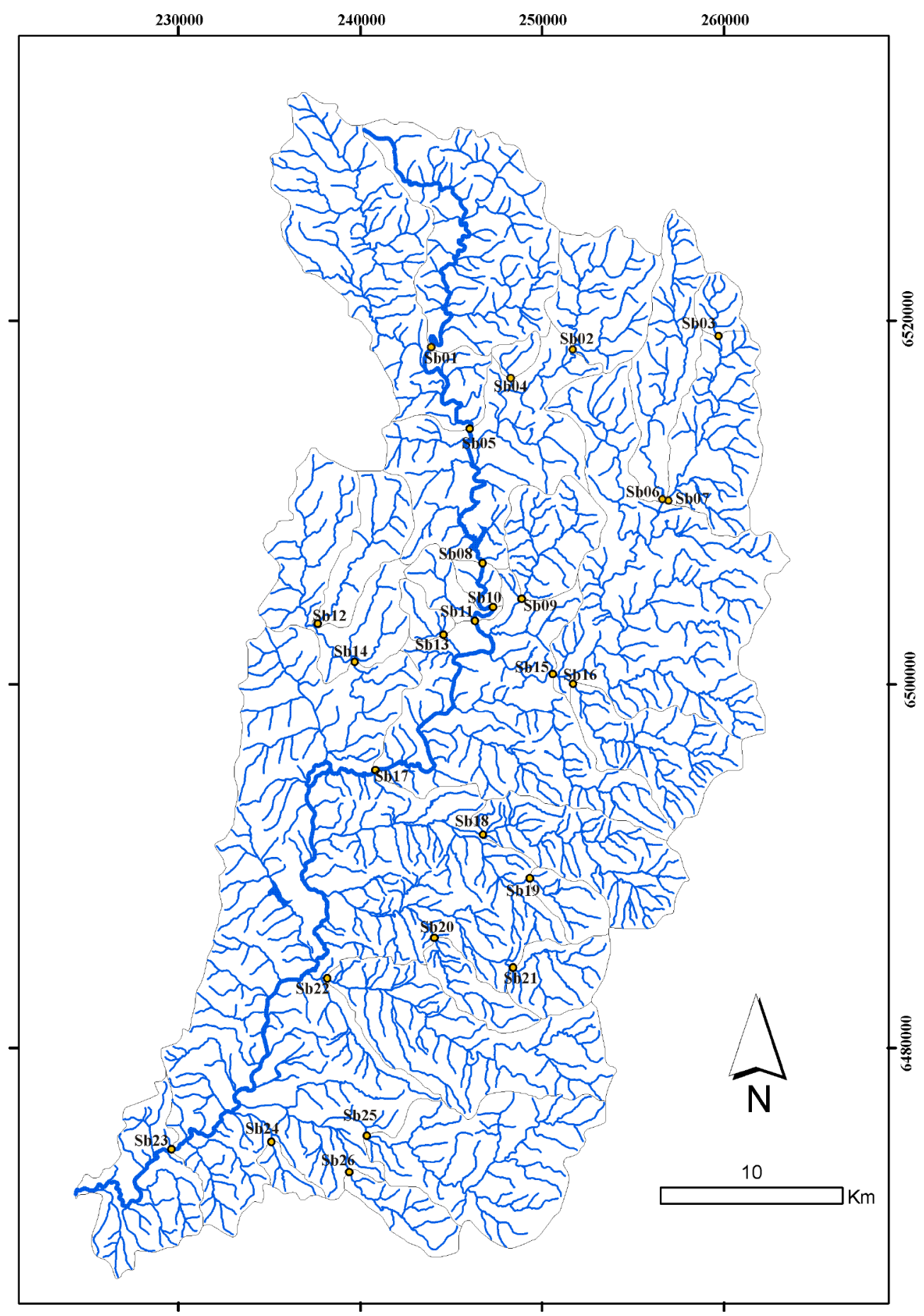

Figura 2. Rede de drenagem da bacia hidrográfica do Arroio Candiota com as 26 sub-bacias (SB's) estudadas. 
ser amostrados in situ. Com isso, futuros estudos poderão utilizar as coordenadas UTM das desembocaduras das sub-bacias (Tab. 1) como locais para medição de variáveis bióticas e abióticas. Isto permitirá investigar a influência dos fatores regionais, naturais e antrópicos, sobre características locais, bióticas e abióticas, dos riachos.

Tabela 1. Coordenadas UTM (zona 22S, Datum Sad 69) das desembocaduras das sub-bacias analisadas.

\begin{tabular}{lcc}
\hline Sub-bacia & Coordenada Sul & Coordenada Leste \\
\hline SB 01 & 6518537 & 243882 \\
SB 02 & 6518444 & 251850 \\
SB 03 & 6519156 & 259697 \\
SB 04 & 6516853 & 248264 \\
SB 05 & 6514441 & 245580 \\
SB 06 & 6510063 & 256640 \\
SB 07 & 6510046 & 256684 \\
SB 08 & 6506688 & 246817 \\
SB 09 & 6504701 & 248865 \\
SB 10 & 6504256 & 247413 \\
SB 11 & 6503497 & 246305 \\
SB 12 & 6503315 & 237432 \\
SB 13 & 6502839 & 244607 \\
SB 14 & 6501376 & 239736 \\
SB 15 & 6500623 & 250680 \\
SB 16 & 6500110 & 251743 \\
SB 17 & 6495277 & 240825 \\
SB 18 & 6491744 & 246727 \\
SB 19 & 6489327 & 249353 \\
SB 20 & 6485990 & 244190 \\
SB 21 & 6484424 & 238455 \\
SB 22 & 6483755 & 238257 \\
SB 23 & 6474436 \\
SB 24 & 6474828 \\
SB 25 & 6475059 & \\
SB 26 & 6473157 & \\
\hline
\end{tabular}

\subsection{Caracterização morfométrica das sub-bacias}

Neste estudo, foram calculadas 15 variáveis morfométricas (Quadro 1), amplamente empregadas em estudos com análise morfométrica de bacias hidrográficas (e.g. Sreedevi et al., 2005; Mesa, 2006; Bhagwat et al., 2011; Patel et al., 2012). Para o cálculo das variáveis utilizou-se o mapeamento do relevo e da rede de drenagem, na escala
1:50.000, obtidos a partir da Base Cartográfica Vetorial Contínua do Rio Grande do Sul (Hasenack \& Weber, 2010). As medidas foram feitas com auxílio dos softwares Arc GIS 10 e Cartalinx.

\subsection{Uso e cobertura do solo}

O uso e a cobertura do solo foram agrupados em oito classes: água, agricultura, campo degradado, mineração, silvicultura, urbano, vegetação natural e uso misto (Quadro 2). Essa classificação foi feita com base no Mapa de Cobertura Vegetal do Bioma Pampa (Hasenack \& Cordeiro, 2006), até o momento o mapeamento mais recente e mais detalhado do uso e cobertura do solo nessa região.

A distribuição das diferentes classes de uso e cobertura do solo (Fig. 3) e a percentagem que ocupam em cada sub-bacia foram determinadas com auxílio dos softwares ArcGIS 10 e Cartalinx.

\subsection{Análise dos dados}

Para determinar como as sub-bacias se distribuem em função das variáveis morfométricas foi utilizada uma Análise de Componentes Principais (ACP), adequada para fins descritivos e exploratórios e não necessita normalidade dos dados (Jolliffe, 2002; Zuur et al., 2007). Na ACP, um número grande de variáveis é reduzido a um conjunto bem menor, os componentes principais (Jolliffe, 2002), que são vetores formados por combinações lineares das variáveis originais (Legendre \& Legendre, 1998; Zuur et al., 2007). A distância euclidiana foi utilizada como medida de dissimilaridade e a ACP foi calculada com base em matriz de correlação (Zuur et al., 2007).

As variáveis utilizadas na ACP foram: área, maior comprimento, amplitude altimétrica, relação de relevo, razão de circularidade, coeficiente de manutenção, fator topográfico, densidade de drenagem, frequência de riachos, razão de textura, índice de sinuosidade e declive médio do riacho principal. As variáveis razão de comprimento médio e razão de bifurcação não foram utilizadas, pois são dependentes das ordens dos riachos presentes. Por exemplo, seria impossível determinar o comprimento médio dos riachos de ordem 3 para uma sub-bacia de segunda ordem. As análises foram desenvolvidas com auxílio do pacote estatístico Paleontological Statistics - PAST (Hammer et al., 2001). 
Quadro 1. Variáveis morfométricas medidas nas sub-bacias, com descrição do método de obtenção e respectivo(s) autor(es).

\begin{tabular}{|c|c|c|}
\hline Variável Morfométrica & Método de obtenção & Referência \\
\hline $\begin{array}{l}\text { Mc: Maior comprimento da } \\
\text { sub-bacia }\end{array}$ & $\begin{array}{l}\text { Distância vetorial, em km, desde a foz até o ponto mais extremo da sub- } \\
\text { bacia, no divisor de águas, paralelo ao riacho principal }\end{array}$ & Schumm (1956) \\
\hline Aa: Amplitude altimétrica & $\begin{array}{l}A a=A_{\operatorname{máx}}-A_{\min } \\
\mathrm{A}_{\text {máx }}: \text { altitude máxima; } \\
\mathrm{A}_{\text {mín }}: \text { altitude mínima; }\end{array}$ & Schumm (1956) \\
\hline Rr: Relação de Relevo & $\begin{array}{l}R r=\frac{A a}{M c} \\
\text { Aa: amplitude altimétrica } \\
\text { Mc: maior comprimento da sub-bacia }\end{array}$ & Schumm (1956) \\
\hline Dd: Densidade de drenagem & $\begin{array}{l}D d=\frac{C t}{A} \\
\text { Ct: comprimento total da rede de drenagem } \\
\text { A: área da sub-bacia }\end{array}$ & Horton (1945) \\
\hline Fr: Frequência de riachos & $\begin{array}{l}F r=\frac{N_{1}}{A} \\
\mathrm{~N}_{1}: \text { número total de riachos de primeira ordem } \\
\text { A: área da sub-bacia }\end{array}$ & Horton (1945) \\
\hline Rt : Razão de Textura & $\begin{array}{l}R t=\frac{N_{1}}{P} \\
\mathrm{~N}_{1}: \text { número de riachos de primeira ordem } \\
\text { P: perímetro da sub-bacia }\end{array}$ & Smith (1950) \\
\hline Rc: Razão de Circularidade & $\begin{array}{l}R c=\frac{4 \pi A}{P^{2}} \\
\text { A: área da sub-bacia } \\
\text { P: perímetro da sub-bacia }\end{array}$ & $\begin{array}{l}\text { Miller (1953 apud } \\
\text { Schumm, 1956) }\end{array}$ \\
\hline $\begin{array}{l}\text { Cm: Coeficiente de } \\
\text { manutenção }\end{array}$ & $\begin{array}{l}C m=\frac{1}{D d} * 1000 \\
\text { Dd: densidade de drenagem }\end{array}$ & Schumm (1956) \\
\hline Is: Índice de Sinuosidade & $\begin{array}{l}\text { Is }=\frac{C}{C_{\text {vet }}} \\
\text { C: comprimento do riacho principal } \\
\mathrm{C}_{\text {vet }}: \text { comprimento vetorial do riacho principal }\end{array}$ & Schumm (1963) \\
\hline Ft: Fator topográfico & $\begin{array}{l}F t=F r * R r * R c \\
\text { Fr: frequência de riachos } \\
\text { Rr: relação de relevo } \\
\text { Rc: razão de circularidade }\end{array}$ & Morisawa (1962) \\
\hline Dm: Declive médio do riacho & $\begin{array}{l}D m=\frac{A_{c a b}-A_{f o z}}{C} \\
A_{\text {cab }}: \text { altitude na cabeceira } \\
\mathrm{A}_{\text {foz }}: \text { altitude na foz } \\
\text { C: comprimento do riacho principal }\end{array}$ & Sreedevi et al. (2005) \\
\hline Ordem dos riachos & Ordenamento Hierárquico & Strahler (1957) \\
\hline $\begin{array}{l}\text { Cmi: Comprimento médio } \\
\text { do riacho }\end{array}$ & $\begin{array}{l}\mathrm{Cmi}=\frac{\mathrm{Ct} i}{\mathrm{Ni}} \\
\text { Cti: comprimento total dos riachos de ordem i; } \\
\text { Ni: número de riachos de ordem i. }\end{array}$ & Horton (1945) \\
\hline $\begin{array}{l}\text { Rcmi: Razão de } \\
\text { comprimento médio }\end{array}$ & $\begin{array}{l}R c m i=\frac{C t_{i}}{C t_{i-1}} \\
\mathrm{Lt}_{\mathrm{i}}: \text { comprimento médio dos riachos de ordem } \mathrm{i} ; \mathrm{Lt}_{\mathrm{i}-1} \text { : comprimento } \\
\text { médio dos riachos de ordem } \mathrm{i}-1 .\end{array}$ & Horton (1945) \\
\hline Rb: Razão de Bifurcação & $\begin{array}{l}R b i=\frac{N_{i}}{N_{i+1}} \\
\mathrm{~N}_{\mathrm{i}}: \text { número total de segmentos de riacho de ordem } \mathrm{i} ; \mathrm{N}_{\mathrm{i}+1}: \text { número de } \\
\text { segmentos de riacho da ordem superior. }\end{array}$ & Horton (1945) \\
\hline
\end{tabular}


Quadro 2. Classes de uso e cobertura do solo utilizadas neste estudo e classe(s) correspondente(s) no mapeamento original de Hasenack \& Cordeiro (2006).

\begin{tabular}{|l|l|}
\hline Classes originais & Classes utilizadas neste trabalho \\
\hline Água & Água \\
\hline Agricultura de sequeiro e agricultura irrigada & Agricultura \\
\hline $\begin{array}{l}\text { Campo degradado, misto mata nativa/campo/ } \\
\text { uso, misto campo/mato }\end{array}$ & Campo degradado \\
\hline Mineração & Mineração \\
\hline Silvicultura, silvicultura cortada & Silvicultura \\
\hline Mancha urbanizada & Urbano \\
\hline $\begin{array}{l}\text { Campo escudo, campo nativo + mata nativa + } \\
\text { afloramentos, campo nativo seco rupestre, campo } \\
\text { nativo úmido, mata nativa }\end{array}$ & Vegetação natural \\
\hline Uso misto - cultivo em pequenas parcelas & Uso misto \\
\hline
\end{tabular}

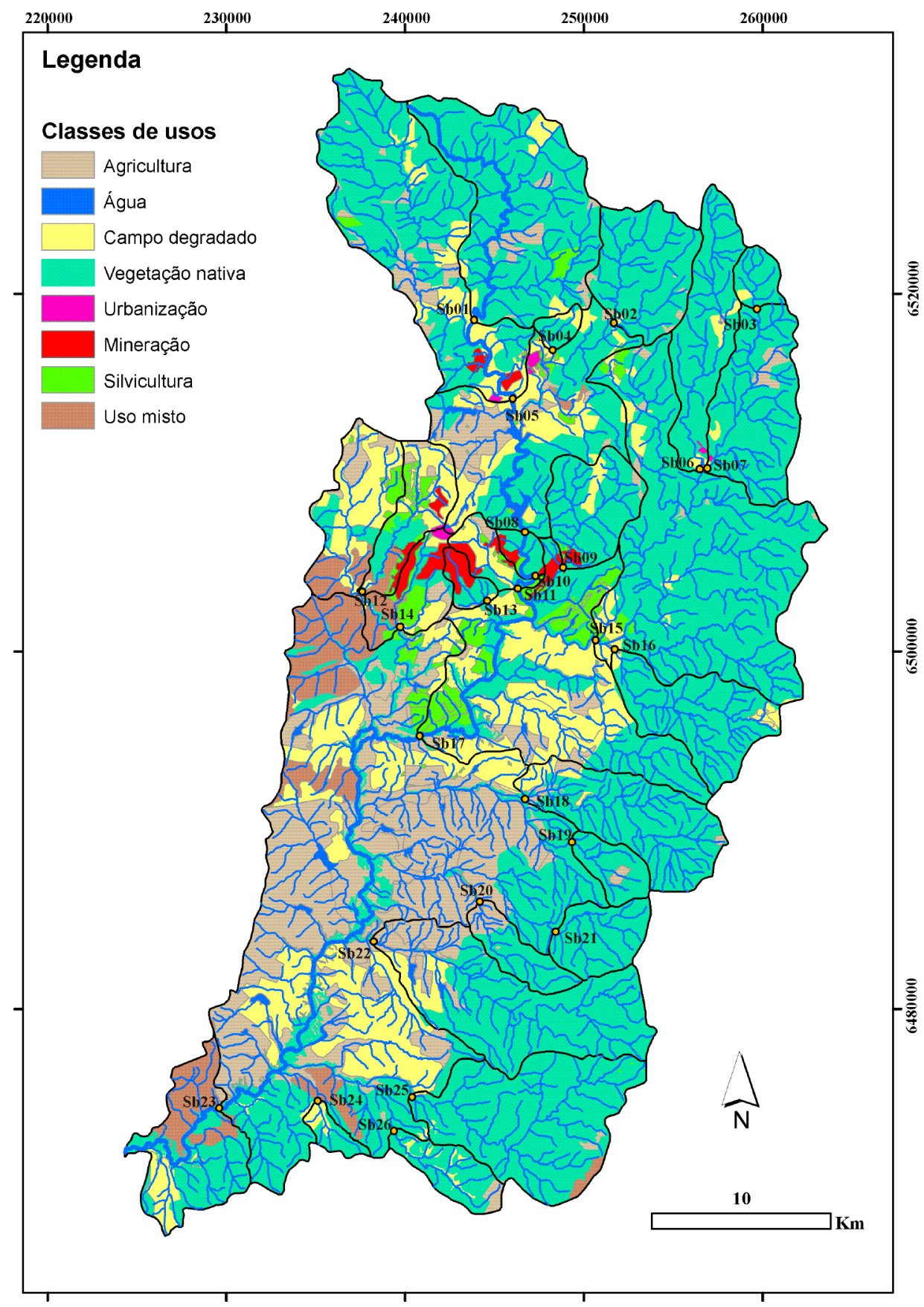

Figura 3. Distribuição das classes de uso e cobertura do solo na bacia hidrográfica do Arroio Candiota e nas 26 sub-bacias (SB’s) analisadas. 


\section{Resultados e Discussão}

\subsection{Caracterização morfométrica das sub-bacias}

A bacia hidrográfica do Arroio Candiota abrange $1.430 \mathrm{~km}^{2}$ e entre as sub-bacias, a área varia de $4,10 \mathrm{~km}^{2}$ a $1.392 \mathrm{~km}^{2}$ (Tab. 2). A área da bacia é fundamental para definir a sua potenciali- dade hídrica e tem grande importância na resposta hidrológica. Se os outros fatores forem desconsiderados, quanto maior a área, menos pronunciados serão os picos de enchentes, pois maior será o tempo para que toda a bacia contribua de uma só vez (Tucci, 1997).

O maior comprimento varia de $2,93 \mathrm{~km}$

Tabela 2. Valores das variáveis morfométricas cuja medição independe da ordem da sub-bacia. A: área da sub-bacia $\left(\mathrm{km}^{2}\right)$, Mc: maior comprimento da sub-bacia $(\mathrm{km})$, Aa: amplitude altimétrica $(\mathrm{m})$, Rr: relação de relevo $\left(\mathrm{m}^{*} \mathrm{~km}^{-1}\right)$, Rc: razão de circularidade, Cm: coeficiente de manutenção, Ft: fator topográfico, Dd: densidade de drenagem $\left(\mathrm{km} / \mathrm{km}^{2}\right)$, Fr: frequência de riachos (riachos* $\mathrm{km}^{-2}$ ), Rt: razão de textura (riachos* $\mathrm{km}^{-1}$ ), Is: Índice de sinuosidade do riacho principal, Dm: declive médio do riacho principal, SB: sub-bacia, BHAC: Bacia Hidrográfica do Arroio Candiota (delimitada a partir de sua desembocadura no rio Jaguarão; ela não é apenas o somatório das outras sub-bacias).

\begin{tabular}{|c|c|c|c|c|c|c|c|c|c|c|c|c|}
\hline Sub-bacia & A & Mc & Aa & $\mathbf{R r}$ & Rc & $\mathrm{Cm}$ & Ft & Dd & $\mathrm{Fr}$ & Rt & Is & Dm \\
\hline SB01 & 86,53 & 12,84 & 163 & 12,69 & 0,58 & 646,53 & 5,99 & 1,55 & 0,81 & 1,62 & 1,19 & 0,007 \\
\hline SB02 & 35,49 & 6,94 & 147 & 21,18 & 0,72 & 734,34 & 9,03 & 1,36 & 0,59 & 0,84 & 1,06 & 0,014 \\
\hline SB03 & 7,44 & 3,53 & 143 & 40,46 & 0,80 & 676,46 & 26,01 & 1,48 & 0,81 & 0,55 & 1,08 & 0,030 \\
\hline SB04 & 4,10 & 2,92 & 70 & 23,96 & 0,75 & 789,62 & 8,71 & 1,27 & 0,49 & 0,24 & 0,98 & 0,019 \\
\hline SB05 & 182,45 & 17,70 & 178 & 10,06 & 0,58 & 642,55 & 4,43 & 1,56 & 0,76 & 2,20 & 1,27 & 0,005 \\
\hline SB06 & 37,58 & 16,01 & 183 & 11,43 & 0,35 & 755,06 & 2,25 & 1,32 & 0,56 & 0,57 & 1,06 & 0,009 \\
\hline SB07 & 51,52 & 12,92 & 175 & 13,55 & 0,50 & 643,85 & 5,26 & 1,55 & 0,78 & 1,11 & 1,16 & 0,009 \\
\hline SB08 & 298,80 & 24,77 & 178 & 7,19 & 0,42 & 681,81 & 2,05 & 1,47 & 0,68 & 2,15 & 1,22 & 0,004 \\
\hline SB09 & 26,92 & 7,25 & 80 & 11,03 & 0,76 & 634,39 & 6,84 & 1,58 & 0,82 & 1,04 & 1,08 & 0,008 \\
\hline SB10 & 304,85 & 27,42 & 198 & 7,22 & 0,40 & 744,71 & 1,96 & 1,34 & 0,67 & 2,11 & 1,20 & 0,004 \\
\hline SB11 & 304,36 & 28,19 & 198 & 7,02 & 0,41 & 668,57 & 1,99 & 1,50 & 0,69 & 2,17 & 1,10 & 0,005 \\
\hline SB12 & 22,17 & 9,33 & 100 & 10,71 & 0,47 & 989,54 & 1,83 & 1,01 & 0,36 & 0,33 & 1,00 & 0,009 \\
\hline SB13 & 5,80 & 3,82 & 122 & 31,93 & 0,61 & 753,67 & 13,44 & 1,33 & 0,69 & 0,37 & 1,03 & 0,024 \\
\hline SB14 & 73,29 & 11,90 & 136 & 11,43 & 0,59 & 890,22 & 2,59 & 1,12 & 0,38 & 0,71 & 1,07 & 0,008 \\
\hline SB15 & 260,12 & 26,20 & 274 & 10,46 & 0,42 & 658,01 & 2,95 & 1,52 & 0,68 & 1,99 & 1,09 & 0,005 \\
\hline SB16 & 36,79 & 10,40 & 217 & 20,86 & 0,52 & 563,34 & 9,64 & 1,78 & 0,90 & 1,10 & 1,10 & 0,015 \\
\hline SB17 & 717,83 & 37,32 & 258 & 6,91 & 0,45 & 671,27 & 2,05 & 1,49 & 0,66 & 3,34 & 1,20 & 0,004 \\
\hline SB18 & 44,92 & 11,63 & 260 & 22,35 & 0,56 & 480,69 & 13,40 & 2,08 & 1,07 & 1,51 & 1,09 & 0,017 \\
\hline SB19 & 10,90 & 4,50 & 160 & 35,57 & 0,71 & 765,00 & 16,13 & 1,31 & 0,64 & 0,50 & 1,01 & 0,031 \\
\hline SB20 & 13,35 & 7,31 & 183 & 25,03 & 0,51 & 598,75 & 10,49 & 1,67 & 0,82 & 0,61 & 1,08 & 0,018 \\
\hline SB21 & 18,62 & 5,58 & 208 & 37,29 & 0,78 & 698,64 & 17,23 & 1,43 & 0,59 & 0,64 & 1,07 & 0,025 \\
\hline SB22 & 70,87 & 16,66 & 288 & 17,29 & 0,44 & 631,21 & 4,74 & 1,58 & 0,62 & 0,98 & 1,10 & 0,010 \\
\hline SB23 & 1391,95 & 57,50 & 278 & 4,83 & 0,41 & 905,42 & 1,27 & 1,10 & 0,65 & 4,36 & 1,24 & 0,003 \\
\hline SB24 & 5,07 & 3,91 & 40 & 10,24 & 0,51 & 655,54 & 4,15 & 1,53 & 0,79 & 0,36 & 1,01 & 0,010 \\
\hline SB25 & 69,21 & 13,28 & 205 & 15,44 & 0,56 & 745,93 & 4,37 & 1,34 & 0,51 & 0,89 & 1,12 & 0,010 \\
\hline SB26 & 14,68 & 6,97 & 140 & 20,09 & 0,58 & 709,83 & 7,14 & 1,41 & 0,61 & 0,50 & 1,07 & 0,015 \\
\hline BHAC & 1431,23 & 63,53 & 374 & 5,88 & 0,36 & 653,19 & 1,41 & 1,53 & 0,66 & 4,24 & 1,24 & 0,002 \\
\hline
\end{tabular}

(SB04) a 57,5 km (SB23) e a amplitude altimétrica de $40 \mathrm{~m}$ (SB24) a $288 \mathrm{~m}$ (SB22) entre as sub-bacias; seu valor tende a aumentar com a área das mesmas (Fig. 4).

A razão de circularidade é baixa na bacia hidrográfica do Arroio Candiota e varia de 0,35 (SB06) a 0,80 (SB03) entre as sub-bacias, com valores maiores nas sub-bacias menores. A circulari- dade de uma bacia hidrográfica é influenciada pelo clima, pelas estruturas geológicas, pelo comprimento e frequência de riachos e pelo relevo (Chopra et al., 2005). De acordo com Wisler \& Brater (1964), a posição dos divisores de água e, consequentemente o formato da bacia hidrográfica são determinados predominantemente por estruturas geológicas como dobras e cadeias de montanhas 
em bacias hidrográficas maiores e por erosão nas bacias menores. Em consequência do seu tamanho reduzido e formato circular, as sub-bacias menores são mais suscetíveis à inundação, visto ser maior a probabilidade de ser atingida simultaneamente por uma tempestade. As sub-bacias maiores, por outro lado, apesar de drenarem áreas maiores e receberem maior aporte hídrico, tendem a ser mais alongadas, tornando mais lento o pico de vazão.

As sub-bacias menores tendem a apresentar maior relação de relevo enquanto a amplitude altimétrica aumenta com a sua área (Fig. 4). A relação de relevo mede a declividade global da bacia hidrográfica e indica a intensidade dos processos de erosão que operam nas encostas das bacias. Por serem mais íngremes, as sub-bacias menores tendem a apresentar maior intensidade dos processos de erosão do seu rio principal. À medida que a área da sub-bacia aumenta, ela passa a abranger regiões de menor altitude, o que aumenta o desnível entre a nascente e a foz, ou seja, a sua amplitude altimétrica.

As sub-bacias estudadas apresentam densidade de drenagem relativamente baixa, com valores entre $1,01 \mathrm{~km} / \mathrm{km}^{2}$ (SB12) e 2,08 km/ $\mathrm{km}^{2}$ (SB18). Segundo Vilella \& Mattos (1975), admite-se que a ela varie de $0,5 \mathrm{~km} / \mathrm{km}^{2}$ para bacias de drenagens pobres, a $3,5 \mathrm{~km} / \mathrm{km}^{2}$ ou mais para bacias excepcionalmente bem drenadas. De acordo com Linsley et al. (1975), uma densidade de drenagem elevada reflete uma bacia altamente dissecada, que responde de maneira relativamente rápida a uma determinada quantidade de chuva, enquanto uma densidade de drenagem baixa reflete uma bacia de drenagem pobre com respostas hidrológicas lentas. As densidades de drenagens baixas são observadas normalmente em solos mais resistentes à erosão ou muito permeável e onde o relevo é suave. Valores altos podem ser esperados em bacias cujos solos são facilmente erodidos ou relativamente impermeáveis, com declividades altas e cobertura vegetal esparsa (Linsley et al., 1975). A densidade de drenagem aumenta com a diminuição da capacidade de infiltração da rocha subjacente e/ou diminuição da capacidade do solo absorver água, ou seja, ela é inversamente proporcional à resistência da litologia subjacente (Sreedevi et al., 2009) e varia inversamente com a extensão do escoamento superficial (Vilella \& Mattos, 1975).

A frequência de riachos apresentou padrão semelhante à densidade de drenagem, com valores entre 0,36 riachos. $\mathrm{km}^{-2}$ (SB12) e 1,07 riachos. $\mathrm{km}^{-2}$ (SB18) nas sub-bacias (Tab. 1). Segundo Christofoletti (1974), a frequência de riachos representa o comportamento hidrográfico de determinada área quanto à sua capacidade de gerar novos cursos de água. Neste estudo, as sub-bacias com maiores valores para a variável frequência de riachos (SB18, SB 20, SB20 e SB09) estão na porção leste da bacia hidrográfica do Arroio Candiota, onde o relevo é mais acidentado.

A variável coeficiente de manutenção, devido à sua fórmula, apresentou padrão exatamente oposto à densidade de drenagem. Essa variável representa, em metros quadrados, a área de drenagem necessária para sustentar um metro linear de canal. A bacia hidrográfica do Arroio Candiota tem coeficiente de manutenção igual a 653,19. Nas sub-bacias, os valores para esta variável oscilam entre 480,69 (SB18) e 989,54 (SB12), com os menores valores observados nas sub-bacias de relevo mais acidentado.

A partir dos valores de razão de circularidade, relação de relevo e frequência de riachos, foi calculado o fator topográfico. De acordo com Morisawa (1962), o valor dessa variável é diretamente proporcional ao potencial de inundação na desembocadura da bacia. Os maiores valores para a variável fator topográfico são observados nas sub-bacias menores, pois apresentam maior relação de relevo e tendem a ser mais circulares (Fig. 4).

Para Smith (1950), a razão de textura pode ser agrupada em muito grossa (Rt $<2,0$ ), grossa $(2,0<\mathrm{Rt}<4,0)$, moderada $(4,0<\mathrm{Rt}<6,0)$, fina $(6,0$ $<\mathrm{Rt}<8,0$ ) e muito fina (Rt $>8,0$ ). De acordo com essa classificação, 77 \% das sub-bacias apresentam razão de textura muito grossa, $19 \%$ apresentam razão de textura grossa e $3 \%$ razão de textura moderada. 0 valor para essa variável tende a aumentar com a área da sub-bacia (Fig. 4).

Schumm (1963) apresenta uma classificação para riachos com base no seu índice de sinuosidade: tortuosos $(2,1)$, irregulares $(1,7)$, regulares $(1,5)$, transicionais $(1,2)$ e retilíneos $(1,0)$. De acordo com esta classificação, os riachos da bacia hidrográfica do Arroio Candiota são pouco sinuosos. A sinuosidade do riacho principal varia de retilínea a transicional em $88 \%$ das sub-bacias e de transicional a regular em $12 \%$ delas. A sinuosidade está relacionada à declividade do riacho e à diversidade de hábitats. Em geral, baixa sinuosidade indica um canal íngreme, com seções transversais uniformes e poucos poços enquanto alta sinuosidade é associada com baixa declividade do riacho, seções transversais assimétricas e poços na porção externa dos meandros (Fitzpatrick et al., 1998). Riachos sinuosos fornecem maior variedade de hábitats para os organismos aquáticos e absorvem melhor a energia associada com o fluxo durante cheias, protegendo o riacho de erosão excessiva (Lazor- 
chack et al., 1998).

As sub-bacias estudadas apresentam baixo declive médio do riacho principal, com valores entre 0,003 (SB23) e 0,031 (SB19). Esta variável é um indicador da quantidade de energia disponível para movimento de água e sedimento ao longo de um riacho e, consequentemente, tem influência direta sobre as características de fluxo, de substrato e do tipo de hábitat presentes (Fitzpatrick et al., 1998). Segundo Vilella \& Mattos (1975), quanto maior o declive do riacho, maior a velocidade de fluxo e mais estreitos e pronunciados serão os hidrogramas de enchente. As sub-bacias menores

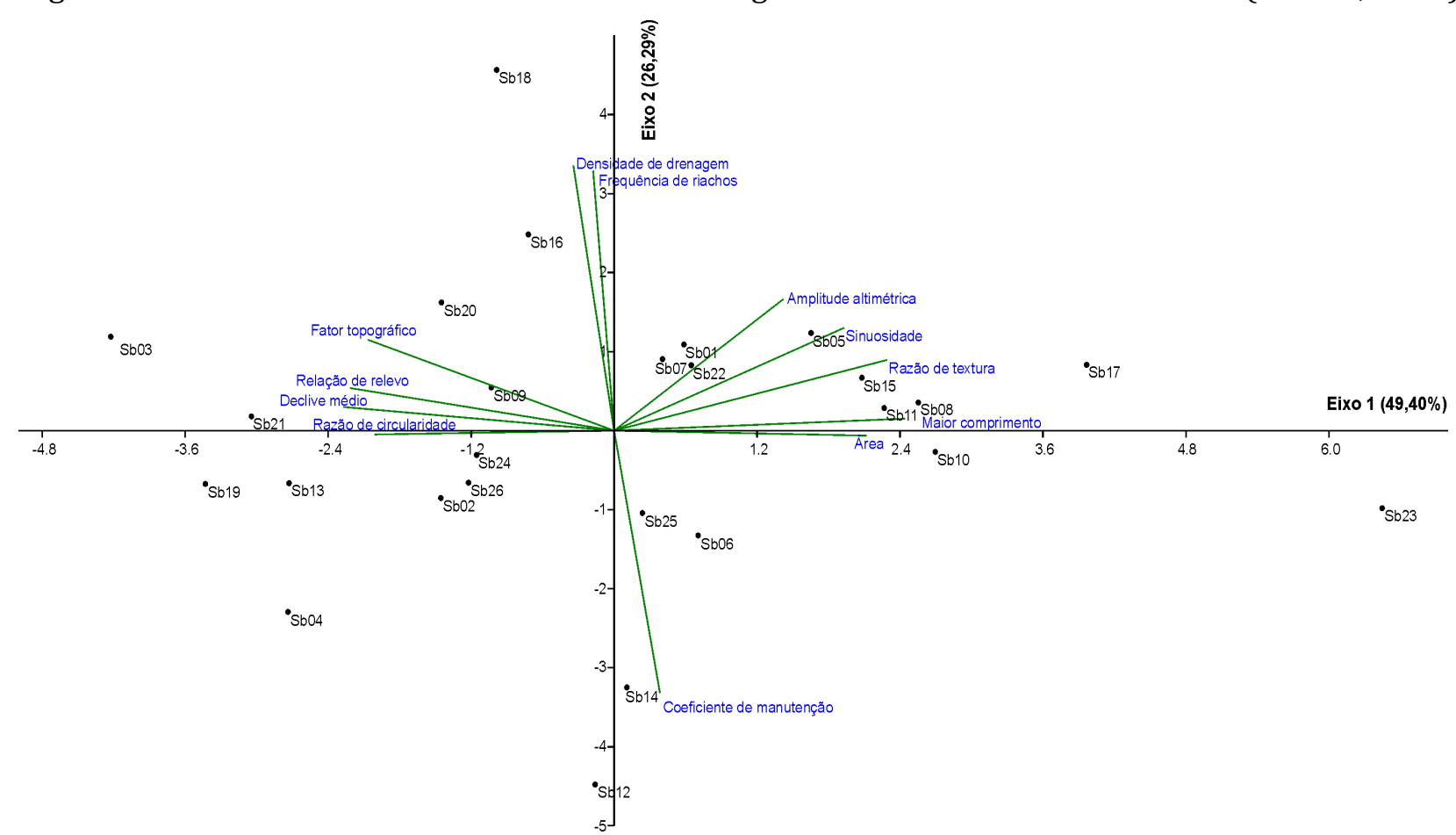

tendem a apresentar maior declive médio do riacho principal (Fig. 4). Logo, é maior a energia associada com o escoamento da água da chuva nessas sub-bacias.

A bacia hidrográfica do Arroio Candiota é uma bacia de sexta ordem e possui dois riachos de quinta ordem, dez de quarta, 37 de terceira, $198 \mathrm{de}$ segunda e 943 riachos de primeira. Das sub-bacias avaliadas, $23 \%$ são de segunda ordem, $19 \%$ de terceira, $31 \%$ de quarta, $19 \%$ de quinta e $8 \%$ de sexta (Tab. 3).As sub-bacias avaliadas apresentam razão de bifurcação entre 2,0 (SB04) e 11,0 (SB20). Segundo a "lei do número de canais" (Horton, 1945),

Figura 4. Análise de Componentes Principais das variáveis morfométricas cuja medição independe da ordem das sub-bacias (Tab.1).

o número de canais de cada ordem forma uma série geométrica inversa com o número de ordem. A razão de bifurcação tende a ser constante e geralmente varia entre 3,0 e 5,0, porém não será exatamente a mesma de uma ordem a outra (Strahler, 1964). Segundo este autor, valores extremamente altos deste índice podem ser esperados em regiões de vales rochosos escarpados e vão sugerir bacias alongadas com hidrogramas apresentando o mesmo formato. Essas regiões geralmente apresentam numerosos tributários de pequena extensão, enquanto nas regiões planas de solo profundo e permeável somente os tributários relativamente longos permanecem (Wisler \& Brater, 1964).

Nas sub-bacias avaliadas, a maior variação da razão de comprimento médio ocorreu na sub-bacia SB23 $(0,1$ a 23,6$)$. A relação dos comprimentos tende a ser constante ao longo das sucessivas ordens de uma bacia (Horton, 1945). Segundo este autor, o comprimento médio dos canais de cada uma das sucessivas ordens de uma bacia tende a aumentar aproximadamente segundo uma progressão geométrica. De acordo com Sreedevi et al. (2005), a razão de comprimento médio varia entre as sucessivas ordens dos riachos devido a diferenças no declive e nas condições topográficas e está relacionada com o fluxo de água superficial e com o estágio erosional da bacia hidrográfica.

\subsection{Usos do solo nas sub-bacias}

A bacia hidrográfica do Arroio Candiota apresentou predomínio da classe vegetação natural, que ocupou 59,31 \% da área da bacia. Dessa forma, apenas 40,69\% da extensão da bacia encontra-se diretamente alterada por atividades antrópicas. É importante destacar que essa informação se ba- 
seia em avaliação feita por sensoriamento remoto, em escala regional. Dessa forma, mesmo as regiões com vegetação natural podem apresentar influência antrópica se for aumentado o nível de detalhamento da avaliação. Das demais classes, campo degradado ocupou a segunda maior área $(15,92$ $\%$ ), seguido de agricultura $(15,81 \%)$, uso misto $(4,21 \%)$, silvicultura $(2,88 \%)$, mineração (1 \%), água $(0,71 \%)$ e urbanização $(0,15 \%)$. Na maior parte das sub-bacias, vegetação natural foi a classe predominante, porém nas sub-bacias SB12 e SB14 houve predomínio da classe campo degradado e na sub-bacia SB13 as classes vegetação natural e mineração ocuparam proporções semelhantes (Tab. 4).Algumas atividades antrópicas têm a sua distribuição espacial associada a características do relevo e da rede de drenagem na bacia hidrográfica do Arroio Candiota. Por exemplo, a classe

Tabela 3. Variáveis morfométricas cuja medição depende da ordem da sub-bacia. N1: número de riachos de primeira ordem, N2: número de riachos de segunda ordem, N3: número de riachos de terceira ordem, N4: número de riachos de quarta ordem, N5: número de riachos de quinta ordem, N6: número de riachos de sexta ordem, Rcm2: razão de comprimento médio 2, Rcm3: razão de comprimento médio 3, Rcm4: razão de comprimento médio 4, Rcm5: razão de comprimento médio 5, Rcm6: razão de comprimento médio 6, Rb1: razão de bifuração 1, Rb2: razão de bifurcação 2, Rb3: razão de bifurcação 3, Rb4: razão de bifurcação 4, Rb5: razão de bifurcação 5.

\begin{tabular}{|c|c|c|c|c|c|c|c|c|c|c|c|c|c|c|c|c|}
\hline $\begin{array}{l}\text { Sub- } \\
\text { bacia }\end{array}$ & N1 & N2 & N3 & N4 & N5 & N6 & Rcm2 & Rcm3 & Rcm4 & Rcm5 & Rcm6 & Rb1 & $\mathbf{R b} 2$ & Rb3 & Rb4 & Rb5 \\
\hline SB01 & 70 & 16 & 3 & 1 & 0 & 0 & 1,36 & 2,36 & 3,35 & 0,00 & 0,00 & 4,38 & 5,33 & 3,00 & 0,00 & 0,00 \\
\hline SB02 & 21 & 6 & 2 & 1 & 0 & 0 & 1,68 & 1,43 & 0,19 & 0,00 & 0,00 & 3,50 & 3,00 & 2,00 & 0,00 & 0,00 \\
\hline SB03 & 6 & 1 & 0 & 0 & 0 & 0 & 2,19 & 0,00 & 0,00 & 0,00 & 0,00 & 6,00 & 0,00 & 0,00 & 0,00 & 0,00 \\
\hline SB04 & 2 & 1 & 0 & 0 & 0 & 0 & 0,20 & 0,00 & 0,00 & 0,00 & 0,00 & 2,00 & 0,00 & 0,00 & 0,00 & 0,00 \\
\hline SB05 & 138 & 29 & 5 & 2 & 1 & 0 & 1,40 & 2,33 & 2,50 & 0,47 & 0,00 & 4,76 & 5,80 & 2,50 & 2,00 & 0,00 \\
\hline SB06 & 21 & 4 & 1 & 0 & 0 & 0 & 1,09 & 9,94 & 0,00 & 0,00 & 0,00 & 5,25 & 4,00 & 0,00 & 0,00 & 0,00 \\
\hline SB07 & 40 & 10 & 3 & 1 & 0 & 0 & 1,58 & 0,97 & 3,91 & 0,00 & 0,00 & 4,00 & 3,33 & 3,00 & 0,00 & 0,00 \\
\hline SB08 & 203 & 47 & 9 & 3 & 1 & 0 & 1,27 & 2,28 & 2,73 & 1,54 & 0,00 & 4,32 & 5,22 & 3,00 & 3,00 & 0,00 \\
\hline SB09 & 22 & 4 & 2 & 1 & 0 & 0 & 0,95 & 1,49 & 1,40 & 0,00 & 0,00 & 5,50 & 2,00 & 2,00 & 0,00 & 0,00 \\
\hline SB10 & 205 & 47 & 9 & 3 & 1 & 0 & 1,27 & 0,01 & 2,73 & 1,89 & 0,00 & 4,36 & 5,22 & 3,00 & 3,00 & 0,00 \\
\hline SB11 & 209 & 48 & 9 & 3 & 1 & 0 & 1,30 & 2,23 & 2,73 & 2,07 & 0,00 & 4,35 & 5,33 & 3,00 & 3,00 & 0,00 \\
\hline SB12 & 8 & 1 & 0 & 0 & 0 & 0 & 5,52 & 0,00 & 0,00 & 0,00 & 0,00 & 8,00 & 0,00 & 0,00 & 0,00 & 0,00 \\
\hline SB13 & 4 & 1 & 0 & 0 & 0 & 0 & 0,39 & 0,00 & 0,00 & 0,00 & 0,00 & 4,00 & 0,00 & 0,00 & 0,00 & 0,00 \\
\hline SB14 & 28 & 7 & 2 & 1 & 0 & 0 & 2,83 & 0,89 & 0,02 & 0,00 & 0,00 & 4,00 & 3,50 & 2,00 & 0,00 & 0,00 \\
\hline SB15 & 176 & 35 & 9 & 2 & 1 & 0 & 1,25 & 3,43 & 2,61 & 0,03 & 0,00 & 5,03 & 3,89 & 4,50 & 2,00 & 0,00 \\
\hline SB16 & 33 & 7 & 2 & 1 & 0 & 0 & 0,72 & 3,64 & 1,83 & 0,00 & 0,00 & 4,71 & 3,50 & 2,00 & 0,00 & 0,00 \\
\hline SB17 & 472 & 97 & 22 & 6 & 2 & 1 & 1,24 & 2,84 & 2,29 & 1,30 & 0,92 & 4,87 & 4,41 & 3,67 & 3,00 & 2,00 \\
\hline SB18 & 48 & 10 & 1 & 0 & 0 & 0 & 0,79 & 11,37 & 0,00 & 0,00 & 0,00 & 4,80 & 10,00 & 0,00 & 0,00 & 0,00 \\
\hline SB19 & 7 & 2 & 1 & 0 & 0 & 0 & 0,84 & 1,25 & 0,00 & 0,00 & 0,00 & 3,50 & 2,00 & 0,00 & 0,00 & 0,00 \\
\hline SB20 & 11 & 1 & 0 & 0 & 0 & 0 & 4,00 & 0,00 & 0,00 & 0,00 & 0,00 & 11,00 & 0,00 & 0,00 & 0,00 & 0,00 \\
\hline SB21 & 11 & 3 & 1 & 0 & 0 & 0 & 1,09 & 2,39 & 0,00 & 0,00 & 0,00 & 3,67 & 3,00 & 0,00 & 0,00 & 0,00 \\
\hline SB22 & 44 & 10 & 2 & 1 & 0 & 0 & 1,09 & 3,57 & 0,49 & 0,00 & 0,00 & 4,40 & 5,00 & 2,00 & 0,00 & 0,00 \\
\hline SB23 & 905 & 193 & 41 & 10 & 2 & 1 & 0,12 & 4,15 & 23,64 & 1,31 & 3,21 & 4,69 & 4,71 & 4,10 & 5,00 & 2,00 \\
\hline SB24 & 4 & 1 & 0 & 0 & 0 & 0 & 1,17 & 0,00 & 0,00 & 0,00 & 0,00 & 4,00 & 0,00 & 0,00 & 0,00 & 0,00 \\
\hline SB25 & 35 & 8 & 2 & 1 & 0 & 0 & 1,09 & 0,89 & 4,78 & 0,00 & 0,00 & 4,38 & 4,00 & 2,00 & 0,00 & 0,00 \\
\hline SB26 & 9 & 3 & 1 & 0 & 0 & 0 & 0,46 & 6,48 & 0,00 & 0,00 & 0,00 & 3,00 & 3,00 & 0,00 & 0,00 & 0,00 \\
\hline BHAC & 943 & 198 & 37 & 10 & 2 & 1 & 1,32 & 2,78 & 2,22 & 1,25 & 3,87 & 4,76 & 5,35 & 3,70 & 5,00 & 2,00 \\
\hline
\end{tabular}

vegetação natural está mais concentrada na região mais montanhosa, na metade leste (Fig. 3). A classe mineração, por outro lado, está concentrada na região central, e assim como a classe silvicultura, mostrou-se mais associada às regiões próximas às nascentes dos riachos. As classes agricultura e campo degradado estão distribuídas principalmente próximas ao curso principal do Arroio Candiota, em especial a jusante da estação amostral SB17, no seu curso inferior. Segundo Allan (2004), as classes de uso e cobertura do solo se sobrepõem a gradientes naturais como litologia, tipos de solo 
e topografia. Essa associação entre a distribuição espacial das características naturais e do uso e cobertura do solo precisa ser considerada em estudos que visem avaliar a influência relativa de fatores regionais naturais e antrópicos sobre padrões e processos observados localmente nos riachos.

As mudanças nos usos do solo podem acarretar em diversos impactos para as bacias hidrográficas e para os ecossistemas fluviais. A remoção da vegetação natural na bacia pode alterar o padrão natural do sistema de drenagem, assim como a taxa na qual a água e o sedimento escoam da bacia hidrográfica para os rios (Gordon et al., 2004). Segundo Eccker (1984), a vegetação também diminui a erodibilidade da superfície, pois protege o solo do impacto da água da chuva e mantém os horizontes superiores do solo ligados por suas raízes.

$A$ atividade agrícola em uma bacia hidrográfica resulta no aumento da quantidade de sedimento no canal, redução da variabilidade de profundidades e redução na complexidade do substrato presente no leito (Walser \& Bart Jr., 1999). Essas reduções na heterogeneidade de profundidades e na complexidade do substrato, associadas com sedimentação, afetam a disponibilidade e a qualidade dos hábitats em poços e corredeiras. Segundo Allan et al. (1997), na bacia do rio Raisin, a extensão da sub-bacia ocupada por agricultura é o melhor preditor das condições locais dos riachos. A agricultura aumenta a quantidade de solo exposto Tabela 4. Percentagem de cada classe de uso do solo nas 26 sub-bacias avaliadas. SB: sub-bacia, BHAC: Bacia Hidrográfica do Arroio Candiota.

\begin{tabular}{|c|c|c|c|c|c|c|c|c|}
\hline $\begin{array}{l}\text { Sub- } \\
\text { bacia }\end{array}$ & $\begin{array}{c}\text { Vegetação } \\
\text { natural }\end{array}$ & Agricultura & $\begin{array}{c}\text { Campo } \\
\text { degradado }\end{array}$ & Urbano & Mineração & Silvicultura & $\begin{array}{c}\text { Uso } \\
\text { misto }\end{array}$ & Água \\
\hline SB01 & 85,55 & 6,93 & 5,52 & 0,00 & 0,00 & 1,98 & 0,00 & 0,03 \\
\hline SB02 & 95,67 & 3,55 & 0,78 & 0,00 & 0,00 & 0,00 & 0,00 & 0,00 \\
\hline SB03 & 93,29 & 0,00 & 6,71 & 0,00 & 0,00 & 0,00 & 0,00 & 0,00 \\
\hline SB04 & 70,28 & 0,00 & 26,01 & 0,00 & 0,00 & 3,71 & 0,00 & 0,00 \\
\hline SB05 & 77,32 & 8,15 & 11,61 & 0,18 & 1,02 & 1,52 & 0,00 & 0,19 \\
\hline SB06 & 92,86 & 0,28 & 6,08 & 0,62 & 0,00 & 0,00 & 0,00 & 0,16 \\
\hline SB07 & 92,31 & 5,21 & 2,21 & 0,23 & 0,00 & 0,00 & 0,00 & 0,05 \\
\hline SB08 & 70,90 & 9,82 & 14,67 & 0,40 & 0,63 & 1,62 & 0,28 & 1,68 \\
\hline SB09 & 85,11 & 2,37 & 8,02 & 0,00 & 3,42 & 1,08 & 0,00 & 0,00 \\
\hline SB10 & 70,81 & 9,67 & 14,38 & 0,47 & 0,98 & 1,76 & 0,28 & 1,65 \\
\hline SB11 & 69,20 & 9,64 & 15,30 & 0,45 & 1,53 & 2,00 & 0,27 & 1,61 \\
\hline SB12 & 20,01 & 5,85 & 36,69 & 0,64 & 8,13 & 21,31 & 7,37 & 0,00 \\
\hline SB13 & 45,99 & 4,22 & 4,40 & 0,00 & 45,39 & 0,00 & 0,00 & 0,00 \\
\hline SB14 & 14,56 & 9,88 & 36,90 & 0,53 & 6,32 & 14,46 & 17,28 & 0,06 \\
\hline SB15 & 91,97 & 1,67 & 5,26 & 0,13 & 0,00 & 0,88 & 0,00 & 0,08 \\
\hline SB16 & 94,31 & 0,00 & 5,69 & 0,00 & 0,00 & 0,00 & 0,00 & 0,00 \\
\hline SB17 & 72,71 & 6,08 & 15,15 & 0,25 & 1,37 & 3,55 & 0,12 & 0,78 \\
\hline SB18 & 87,67 & 4,97 & 7,14 & 0,00 & 0,00 & 0,03 & 0,00 & 0,19 \\
\hline SB19 & 93,47 & 6,53 & 0,00 & 0,00 & 0,00 & 0,00 & 0,00 & 0,00 \\
\hline SB20 & 76,01 & 23,99 & 0,00 & 0,00 & 0,00 & 0,00 & 0,00 & 0,00 \\
\hline SB21 & 100,00 & 0,00 & 0,00 & 0,00 & 0,00 & 0,00 & 0,00 & 0,00 \\
\hline SB22 & 75,59 & 15,63 & 7,85 & 0,00 & 0,00 & 0,00 & 0,00 & 0,93 \\
\hline SB23 & 59,57 & 16,23 & 15,95 & 0,16 & 1,04 & 2,96 & 3,36 & 0,73 \\
\hline SB24 & 65,42 & 0,14 & 33,67 & 0,00 & 0,00 & 0,00 & 0,77 & 0,00 \\
\hline SB25 & 95,67 & 1,27 & 0,53 & 0,00 & 0,00 & 0,22 & 2,31 & 0,00 \\
\hline SB26 & 74,67 & 10,13 & 15,20 & 0,00 & 0,00 & 0,00 & 0,00 & 0,00 \\
\hline ВНАC & 59,31 & 15,81 & 15,92 & 0,15 & 1,01 & 2,88 & 4,21 & 0,71 \\
\hline
\end{tabular}

na bacia hidrográfica, o que aumenta o aporte de sedimento fino para os rios e, consequentemente, o grau de soterramento (embeddedness) dos substratos maiores nos riachos (Richards \& Host, 1994). Dessa forma, espaços entre pedregulhos, seixos e galhos são soterrados e deixam de servir de hábitat para peixes e invertebrados aquáticos.

Atividades como a mineração podem ocasionar mudanças até mesmo na topografia da bacia hidrográfica, incluindo relevo, declive, largura do canal, sinuosidade, capacidade de infiltração e permeabilidade do solo e cobertura vegetal (Eccker, 1984). A urbanização, embora normalmente ocupe um pequeno percentual da bacia hidrográfica, exerce uma influência desproporcionalmente grande sobre a qualidade da água nos riachos (Zhou et al., 2012). Além disso, de acordo com Richards \& Host (1994), o tamanho do substrato nos riachos diminui com o aumento da extensão da bacia ocupada por urbanização e a silvicultura pode alterar as taxas nas quais troncos e galhos entram nos riachos. Os troncos e galhos podem servir como hábitats para espécies de peixes e invertebrados aquáticos que os utilizam como locais para refúgio, alimentação e reprodução.

\section{Conclusões}

As sub-bacias contribuintes da bacia hidrográfica do Arroio Candiota possuem grande variação quanto aos seus tamanhos, baixa densidade

\author{
(1)
}


de drenagem e rios pouco sinuosos. As sub-bacias menores têm formato mais circular, maior declive do rio principal e maior fator topográfico, o que as torna mais suscetíveis a inundações. As sub-bacias maiores, por sua vez, apresentam maior textura no relevo, formato menos circular e declive mais suave. A densidade de drenagem, a frequência de riachos e a razão de bifurcação tendem a ser maiores nas regiões com relevo mais acidentado.

A maior parte da bacia hidrográfica do Arroio Candiota está ocupada pela classe vegetação natural, seguida de campo degradado, agricultura, uso misto, silvicultura, mineração, água e urbanização. Algumas classes de uso e cobertura do solo têm sua distribuição espacial associada a características do relevo e da rede de drenagem. A classe vegetação natural está concentrada principalmente na metade leste da bacia hidrográfica do Arroio Candiota, onde o relevo é mais acidentado. Mineração e silvicultura ocorrem próximas a riachos de primeira ordem e a classe agricultura ocorre principalmente próxima ao curso inferior do Arroio Candiota, em áreas de planície e com maior disponibilidade de água.

Este estudo demonstra que tanto as características morfométricas quanto os usos do solo variam entre as sub-bacias que compõem a bacia hidrográfica do Arroio Candiota. Tendo em vista que um sistema fluvial é organizado hierarquicamente, a variação espacial nas características regionais antrópicas e naturais determinará muitos padrões e processos locais, bióticos e abióticos nos riachos. Dessa forma, os resultados apresentados deverão ser considerados em futuros estudos que visem entender como os padrões e processos interagem entre as diversas escalas espaciais que compõem um sistema fluvial.

Agradecimentos - Os resultados deste estudo são parte da dissertação de mestrado do autor sênior. Os autores agradecem ao Conselho Nacional de Desenvolvimento Científico e Tecnológico (CNPq) e ao Programa de Pósgraduação em Ecologia da Universidade Federal do Rio Grande do Sul (UFRGS) pela bolsa de estudos recebida, e ao Laboratório de Geoprocessamento do Centro de Ecologia (LabGeo - UFRGS) pelo auxílio em relação ao geoprocessamento.

\section{Referências}

Allan, J.D. 2004. Landscapes and riverscapes: the influence of land use on stream ecosystems. Annual reviews of ecology, evolution and systematics, 35: 257-284.

Allan, J.D., Erickson, D.L. \& Fay, J. 1997. The influence of catchment land use on stream integrity across multiple spatial scales. Freshwater Biology, 37: 149-161.

Bhagwat, T.N., Shetty, A. \& Hegde, V.S. 2011. Spatial va- riation in drainage characteristics and geomorphic instantaneous unit hydrograph (GIUH): implications for watershed management - a case study of the Varada River basin, Northern Karnataka. Catena, 87: 52-59.

Christofoletti, A. 1974. Geomorfologia. São Paulo: Edgard Blucher, $189 \mathrm{p}$.

Chopra, R., Dhiman, R.D. \& Sharma, P.K. 2005. Morphometric analysis of sub-watersheds in Gurdaspur District, Punjab using remote sensing and GIS techniques. Journal of the Indian Society of Remote Sensing, 33(4): 531-535.

CPRM. Serviço Geológico do Brasil. 2000. Programa Levantamentos Geológicos Básicos do Brasil - Carta Geológica Folha SH.22-Y-C, Pedro Osório. Brasília, Departamento de Geologia. Escala 1:250.000.

Cunha, N.G. da, Silveira, R.J.C. da, Severo, C.R.S., Soares, M.J., Santos, C.N. dos, Fontoura Júnior, E.R. \& Silva, C. 1998. Estudo dos solos do município de Candiota. Pelotas, EMBRAPA-CPACT. (EMBRAPA-CPACT. Circular Técnica, 11).

Eccker, S. L. 1984. The effect of lithology and climate on the morphology of drainage basins in Northwestern Colorado. Colorado, Colorado Water Resources Research Institute. (Completion Report 131).

Eger, P.M. 2012. Análise da dinâmica da paisagem a partir da vegetação na bacia hidrográfica do Arroio Candiota - RS. Canoas, 128 p. Dissertação de Mestrado, Programa de Pós-graduação em Avaliação de Impactos Ambientais em Mineração, Centro Universitário La Salle.

Fitzpatrick, F.A., Waite, I.R., D'Arconte, P.J., Meador, M.R., Maupin, M.A. \& Gurtz, M.E. 1998. Revised Methods for Characterizing Stream Habitat in the National Water-Quality Assessment Program. North Carolina, United States Geological Survey. (Water-Resources Investigations Report 98-4052). 67 p.

Frissel, C.A., Liss, W.J., Warren, C.E. \& Hurley, M.D. 1986. A hierarchical framework for stream habitat classification: viewing streams in a watershed context. Environmental Management, 10 (2): 199-214.

Gergel, S.E., Turner, M.G., Miller, J.R., Mellack, J.M. \& Stanley, E.H. 2002. Landscape indicators of human impacts to riverine systems. Aquatic Sciences, 64: 118-128.

Gordon, N.D., McMahon,T.A., Finlayson, B.L., Gippel, C.J. \& Nathan, R.J. 2004. Stream Hydrology: an introduction for ecologists. $2^{\text {a. }}$ ed., West Sussex, John Wyley \& Sons, $429 \mathrm{p}$.

Guerra, T. \& Ferraro, L.W. 2004. Caracterização geral da região de Candiota. In: Teixeira, E.B.C. \& Pires, M.J.R. (coords.). Estudos Ambientais em Candiota: carvão e seus impactos. Porto Alegre, FEPAM/FINEP/PDACT/ CIAMB/FAPERGS, (Cadernos de planejamento e gestão ambiental, no 02), p. 17-27.

Hammer, Ø., Harper, D.A.T. \& Ryan, P.D. 2001. PAST: Paleontological statistics software package for education and data analysis. Palaeontologia Electronica, 4(1): 9pp. Disponível em: <http://palaeo-electronica. org/2001_1/past/issue1_01.htm>. Acesso em: 02 fev. 2014. 
Hasenack, H. \& Cordeiro, J.L.P. (org.). 2006. Mapeamento da cobertura vegetal do Bioma Pampa. Porto Alegre, UFRGS Centro de Ecologia, 30 p. (Relatório técnico Ministério do Meio Ambiente: Secretaria de Biodiversidade e Florestas no âmbito do mapeamento da cobertura vegetal dos biomas brasileiros).

Hasenack, H. \& Weber, E. (Org.). 2010. Base cartográfica vetorial contínua do Rio Grande do Sul: escala 1:50.000. Porto Alegre, UFRGS, Instituto de Biociências, Centro de Ecologia, 1 DVD. (Série Geoprocessamento, 3). Dados espaciais digitais georreferenciados ao SIRGAS2000 (Sistema de Referência Geocêntrico para as Américas).

Horton, R.E. 1945. Erosional development streams and their drainage basins: hidrophysical approach to quantitative morphology. Bulletin Geological Society of America, 56: 275-370.

Jolliffe, I.T. 2002. Principal Component Analysis. 2a. ed., New York, Springer. 489 p.

Lazorchak, J.M., Herlihy, A.T. \& Green, J. 1998. Rapid habitat and visual stream assessments. In: Lazorchak, J. M., Klemm, D.J. \& Peck, D.V. (eds.). Environmental monitoring and assessment program surface waters: field operations and methods for measuring the ecological condition of wadeable streams. EPA/620/R94/004F. Washington, D.C., U. S. Environmental Protection Agency, p. 193-210.

Legendre, P. \& Legendre L. 1998. Numerical Ecology. 2a. ed., Amsterdam, Elsevier, 853 p.

Linsley, R.K., Kohler, M.A., \& Paulhus, J.L. H. 1975. Hydrology for Engineers. 2. ed., New York, McGraw-Hill (McGraw-Hill Series in Water Resources and Environmental Engineering), $482 \mathrm{p}$.

Mesa, L.M. 2006. Morphometric analysis of a subtropical Andean basin (Tucumán, Argentina). Environmental Geology, 50: 1235-1242.

Morisawa, M.E. 1962. Qualitative geomorphology of some watersheds in the Appalachian Plateau. Geological Society of America Bulletin, 73(9): 1025-1046.

Patel, D.P., Gajjar, C.A. \& Srivastava, P.K. 2012. Prioritization of Malesari mini-watersheds through morphometric analysis: a remote sensing and GIS perspective. Environmental Earth Sciences, 69: 2643-2656.

Richards, C. \& Host, G. 1994. Examining land use influences on stream habitats and macroinvertebrates: a GIS approach. Water Resources Bulletin, 30 (4): 72938.

Richards, C., Johnson, L.B. \& Host, G.E. 1996. Landscape-influences on stream habitats and biota. $\mathrm{Ca}$ nadian Journal of Fisheries and Aquatic Sciences, 53(supplem. 1): 295-311.

Schumm, S.A. 1956. Evolution of drainage systems and slopes in Badlands at Perth Amboy, New Jersey. Geological Society of America Bulletin, 67: 597-646.

Schumm, S.A. 1963. Sinuosity of aluvial rivers on the Great Plains. Geological Society of America Bulletin, 74: 1089-1100.

Man 541

Editores: Tania Marques Strohaecker \& Maria do

Carmo Lima e Cunha.
Smith, K.G. 1950. Standards for grading textures of erosional topography. American Journal of Science, 248: 655-668.

Sreedevi, P.D., Subrahmanyam, K. \& Ahmed, S. 2005. The significance of morphometric analysis for obtaining groundwater potential zones in a structurally controlled terrain. Environmental Geology, 47: 412-420.

Sreedevi, P.D., Owais, S., Khan, H.H. \& Ahmed, S. 2009. Morphometric analysis of a watershed of South India using SRTM data and GIS. Journal of Geological Society of India, 73: 543-552.

Strahler, A.N. 1957. Quantitative analysis of watershed geomorphology. Transaction American Geophysical Union, 38: 913-920.

Strahler, A.N. 1964. Quantitative geomorphology of drainage basins and channel networks. In: Chow, V. T. (Ed.). Handbook of applied Hidrology. New York, McGraw-Hil, p. 39-76.

Strek, C.D., Teixeira, E.C., Ortiz, L.S. \& Sanchez, J.D. 2004. Estudo da contaminação aquática e estimativa de fluxos de elementos metálicos na região de Candiota/RS. In: Teixeira, E.B.C. \& Pires, M.J.R. (coords). Estudos Ambientais em Candiota: carvão e seus impactos. Porto Alegre, FEPAM/FINEP/PDACT/CIAMB/ FAPERGS, (Cadernos de planejamento e gestão ambiental, no 02, p. 113-125).

Teixeira, E.C. \& Pires, M.J.R. (coords). 2004. Estudos Ambientais em Candiota: carvão e seus impactos. Porto Alegre. FEPAM/FINEP/PDACT/CIAMB/FAPERGS. (Cadernos de planejamento e gestão ambiental, $\mathrm{n}^{\underline{0}}$ 02).

Thomas, J., Joseph, S., Thrivikramji, K., Abe, G. \& Kannan, N. 2012. Morphometrical analysis of two tropical mountain river basins of contrasting environmental settings, the Southern Western Ghats, India. Environmental Earth Sciences, 66 (8): 2353-2366.

Tucci, C.E.M. (org.). 1997. Hidrologia: ciência e aplicação. $2^{\circ}$ ed. Porto Alegre, Editora da Universidade: ABRH, 943 p. (Coleção ABRH de Recursos Hídricos; v. 4)

Vilella, S.M. \& Mattos, A. 1975. Hidrologia aplicada. São Paulo, McGraw-Hill, 245 p.

Walser, C.A. \& Bart Jr., H.L. 1999. Influence of agriculture on in-stream habitat and fish community structure in Piedmont watersheds of the Chattahoochee River System. Ecology of Freshwater Fish, 8: 237-246.

Wisler, C.O. \& Brater, E.F. 1964. Hidrologia. Tradução e publicação de Missão Norte-americana pela Cooperação Econômica e Técnica no Brasil. Rio de Janeiro, Ao Livro Técnico S.A., 484 p.

Zhou, T., Wu, J. \& Peng, S. 2012. Assessing the effects of landscape pattern on river water quality at multiple scales: A case study of the Dongjiang River watershed, China. Ecological Indicators, 23: 166-175.

Zuur, A.F., Ieno, E.N. \& Smith, G.M. 2007. Analysing ecological data. New York, Springer, 672 p. 